University of Nebraska - Lincoln

DigitalCommons@University of Nebraska - Lincoln

\title{
Where do adaptive shifts occur during invasion? A multidisciplinary approach to unravelling cold adaptation in a tropical ant species invading the Mediterranean area
}

\author{
Olivier Rey \\ INRA, olivier.rey.1@gmail.com \\ Arnaud Estoup \\ INRA, estoup@supagro.inra.fr \\ Merav Vonshak \\ Tel-Aviv University, meravwei@post.tau.ac.il \\ Anne Loiseau \\ INRA, loiseau@supagro.inra.fr \\ Simon Blanchet \\ CNRS
}

See next page for additional authors

Follow this and additional works at: https://digitalcommons.unl.edu/usdaarsfacpub

Rey, Olivier; Estoup, Arnaud; Vonshak, Merav; Loiseau, Anne; Blanchet, Simon; Calcaterra, Luis; Chifflet, Lucila; Rossi, Jean-Pierre; Kergoat, Gael J.; Foucaud, Julien; Orivel, Jérôme; Leponce, Maurice; Schultz, Ted; and Facon, Benoit, "Where do adaptive shifts occur during invasion? A multidisciplinary approach to unravelling cold adaptation in a tropical ant species invading the Mediterranean area" (2012). Publications from USDA-ARS / UNL Faculty. 1121.

https://digitalcommons.unl.edu/usdaarsfacpub/1121

This Article is brought to you for free and open access by the U.S. Department of Agriculture: Agricultural Research Service, Lincoln, Nebraska at DigitalCommons@University of Nebraska - Lincoln. It has been accepted for inclusion in Publications from USDA-ARS / UNL Faculty by an authorized administrator of DigitalCommons@University of Nebraska - Lincoln. 


\section{Authors}

Olivier Rey, Arnaud Estoup, Merav Vonshak, Anne Loiseau, Simon Blanchet, Luis Calcaterra, Lucila Chifflet, Jean-Pierre Rossi, Gael J. Kergoat, Julien Foucaud, Jérôme Orivel, Maurice Leponce, Ted Schultz, and Benoit Facon 


\section{A multidisciplinary approach to unravelling cold adaptation in a tropical ant species invading the Mediterranean area}

\author{
Olivier Rey, ${ }^{1 *}$ Arnaud Estoup, ${ }^{1}$ \\ Merav Vonshak, ${ }^{2}$ Anne Loiseau, ${ }^{1}$ \\ Simon Blanchet, ${ }^{3,4}$ Luis \\ Calcaterra, ${ }^{5}$ Lucila Chifflet, ${ }^{5}$ \\ Jean-Pierre Rossi, ${ }^{1}$ Gaël J. \\ Kergoat, ${ }^{1}$ Julien Foucaud, ${ }^{1}$ \\ Jérôme Orivel, ${ }^{4,6}$ Maurice \\ Leponce, ${ }^{7}$ Ted Schultz ${ }^{8}$ and Benoit \\ Facon $^{1}$
}

\begin{abstract}
Evolution may improve the invasiveness of populations, but it often remains unclear whether key adaptation events occur after introduction into the recipient habitat (i.e. post-introduction adaptation scenario), or before introduction within the native range (i.e. prior-adaptation scenario) or at a primary site of invasion (i.e. bridgehead scenario). We used a multidisciplinary approach to determine which of these three scenarios underlies the invasion of the tropical ant Wasmannia auropunctata in a Mediterranean region (i.e. Israel). Species distribution models (SDM), phylogeographical analyses at a broad geographical scale and laboratory experiments on appropriate native and invasive populations indicated that Israeli populations followed an invasion scenario in which adaptation to cold occurred at the southern limit of the native range before dispersal to Israel. We discuss the usefulness of combining SDM, genetic and experimental approaches for unambiguous determination of eco-evolutionary invasion scenarios.
\end{abstract}

\section{Keywords}

Adaptation, biological invasion, cold temperature, climatic niche shift, Mediterranean zone, Wasmannia auropunctata.

Ecology Letters (2012) 15: 1266-1275

\section{INTRODUCTION}

Evolution is now recognised to facilitate invasion by some populations (e.g. Cox 2004). Evolutionary changes may occur following introduction into a remote new location, as an evolutionary response to new biotic and/or abiotic pressures (Sakai et al. 2001; Cox 2004), hereafter called 'post-introduction adaptation scenario'. Hence, evolutionary changes should occur independently at each area of introduction. For example, the invasive marine copepod Eurytemora affinis has adapted to freshwater habitats independently several times, with the advent of ballast water shipping and discharge into freshwater lakes on several continents (Lee 1999). Two alternative eco-evolutionary invasion scenarios have also recently been proposed to account for the invasiveness of some populations. First, adaptation may occur at a primary site of invasion, with other territories subsequently invaded from this site, a scenario recently called the 'bridgehead scenario' (Lombaert et al. 2010). Adaptive changes may thus occur only once, at the bridgehead locality. The adaptive changes occurring at this site may overcome biotic and/or abiotic barriers to invasion, thereby facilitating subsequent establishment following dispersal to other biogeographical areas with selective pressures similar to those at the bridgehead. Alternatively, key evolutionary changes for the invasion may occur within the native range, before dispersal into the introduced range (Bossdorf et al. 2008; Hufbauer et al. 2012). This scenario has recently been described as 'two-step' (Foucaud et al. 2009) or anthropogenically induced adaptation to invade (AIAI) when this prior adaptation relates to the alteration of habitats by humans (Hufbauer et al. 2012). Hereafter, we used the term 'prior-adaptation', sometimes also called 'pre-adaptation', to refer to this scenario (see Hufbauer et al. 2012 for arguments supporting the term prior-adaptation).

Unravelling the eco-evolutionary scenarios leading to the emergence of invasive populations has important implications both for invasion theory, to improve our understanding of the circumstances favouring adaptive changes during invasion, and for management policies, as it may guide actions for preventing or controlling invasions. However, substantial amounts of information are required to distinguish between eco-evolutionary invasion scenarios and this information has proved difficult to obtain (Hufbauer et al. 2012). The information required includes (1) phenotypic data for both native and introduced populations, to determine whether adaptation occurred during invasion, (2) genetic data for documenting the genetic relationship between native and invasive populations and retracing the invasion route and (3) environmental data (abiotic and/or biotic) to assess the selection pressures acting in both native and introduced populations. Common-garden experiments and

\footnotetext{
${ }^{1}$ INRA, UMR1062, CBGP, Montpellier, France

${ }^{2}$ Department of Zoology, Tel-Aviv University, 69978, Tel-Aviv, Israel ${ }^{3}$ CNRS, Station d'Ecologie Expérimentale du CNRS à Moulis, USR. 2936, 09 200, Moulis, France

${ }^{4}$ CNRS, Laboratoire Evolution et Diversité Biologique, UMR 5174, 118 route de Narbonne, 31 062, Toulouse Cedex, France

${ }^{5}$ US Department of Agriculture, Agricultural Research Service (USDA-ARS), South American Biological Control Laboratory (SABCL), Buenos Aires, Argentina
} 
phenotypic analyses have been successfully used to illustrate the rapid adaptive evolution of invasive populations (e.g. Huey et al. 2000). Genetic tools have also been used to decipher complex invasion histories (e.g. Lombaert et al. 2010; Ascunce et al. 2011). Species distribution models (SDM) have been used to identify ecological niche shifts associated with invasion (e.g. Broennimann et al. 2007). Recently, Lachmuth et al. (2010) highlighted the benefit of combining climatic data with neutral genetic analyses to shed light on the genetic and ecological mechanisms contributing to the invasiveness of populations. However, to our knowledge, experimental, genetic and SDM approaches have never been applied simultaneously to the same species for unambiguous determination of the eco-evolutionary scenario of an invasion.

We conducted an integrative study combining experimental, genetic and SDM approaches, to determine which of the three ecoevolutionary invasion scenarios cited above was responsible for the recent invasion of a Mediterranean region (i.e. Israel; Vonshak et al. 2010) by the tropical ant Wasmannia auropunctata. We first used SDM analyses to identify geographical regions in which native and/or invasive populations of $W$. auropunctata were subject to cold-temperature selection pressures similar to those in Israel. We then conducted a worldwide genetic analysis based on mitochondrial and microsatellite markers, to determine the genetic origin of the Israeli lineage, focusing on populations established in the candidate geographical areas identified in our SDM analysis. Finally, we conducted laboratory experiments to compare the response to cold stress of workers from Israeli populations and workers from a large set of populations from the native and introduced ranges, taking into account the results obtained with the other two approaches (i.e. SDM and genetic analyses). This integrative approach allowed to test (1) whether the establishment of $W$. auropunctata populations in Israel was accompanied by an adaptation of workers to local cold temperature and (2) whether this adaptation occurred within the introduced range in Israel (i.e. post-introduction adaptation scenario), or before transportation to Israel, either at a primary site of invasion (i.e. bridgehead scenario) or in particular habitats within the native range (i.e. prior-adaptation scenario).

\section{MATERIALS AND METHODS}

\section{Study species}

Wasmannia auropunctata originates from the neotropic ecozone, from northern Argentina to Mexico (Wetterer \& Porter 2003), and displays two types of populations within its native range. Ancestral native populations are confined to tropical primary forests, occupying naturally disturbed areas (e.g. floodplains), and are characterised by low nest and worker densities (Wetterer \& Porter 2003; Orivel et al. 2009). Some populations have repeatedly invaded humanmodified habitats within the native range (e.g. road sides, plantations; Orivel et al. 2009). This change of habitat within the native range is associated with a major ecological shift, with high worker and nest densities (Orivel et al. 2009) and a genetic shift in the reproductive system, from a haplo-diploid sexual model to clonally reproducing queens and males (Foucaud et al. 2007, 2009).

Since the beginning of the 20th century, $W$. auropunctata has invaded many countries in tropical and subtropical zones (Wetterer \& Porter 2003; Foucaud et al. 2010). In its introduced range, the invasive populations settle in human-altered habitats and display several traits similar to those of the clonal populations from the native area (i.e. ecological dominance and clonality; Foucaud et al. 2010). In 2005, established populations of $W$. auropunctata were identified in Israel, in the Mediterranean zone, which is characterised by climatic features, including colder winter temperatures, very different from those in the tropical core habitat (Vonshak et al. 2010). Despite these contrasted abiotic conditions, the Israeli populations display nesting and foraging behaviour similar to that observed in tropical and subtropical areas (Vonshak et al. 2010). The ability of foraging workers to cope with cold winter temperatures suggests that the Israeli population may have undergone adaptation to cold temperatures, allowing it to invade this new biogeographical area.

\section{Species distribution modelling analyses}

We used the 'domain' algorithm (Carpenter et al. 1993) to model the distribution of $W$. auropunctata on the basis of 88 georeferenced occurrences in Israel. The occurrences are widely distributed in Israel (Fig. 1b) and hence are likely to represent most of the climatic range that $W$. auropunctata may potentially encounter in this region. Half these occurrences were used for model fitting, the other half being used for model evaluation. The climate data studied included four variables describing the cold-temperature conditions typical of the habitats occupied in Israel: the minimum temperature of the coldest month, the mean temperature of the coldest quarter, the annual mean temperature and the annual temperature range (available from the WORLDCLIM database; Hijmans et al. 2005). Data were managed using GIS GRASS software (GRASS Development Team 2008), interfaced with $R$ via the $R$ packages spgrass6 (Bivand 2011) and raster (Hijmans \& van Etten 2010). Models were fitted and evaluated using the $\mathrm{R}$ package dismo (Hijmans et al. 2010).

We evaluated the performance of the models for the Israeli region, by comparing model predictions with observations, by calculating the area under the curve (AUC) of a receiver operating characteristics plot (Fielding \& Bell 1997). As only data for occurrences were available, pseudoabsences were generated at random for the geographical region over which the model was defined (Fig. 1b). The domain algorithm yielded a model that was ultimately used to identify geographical regions worldwide with similar climatic conditions and in which $W$. auropunctata populations had previously been reported.

This above simple method was used because it shows a low risk of overfitting the data and hence a robust transferability to other remote geographical regions (Carpenter et al. 1993). We nevertheless conducted a complementary analysis based on the multivariate environmental similarity surface (MESS) approach (Elith et al. 2010; see Appendix S1 in supporting information). Because species distribution models assume that records represent a species at equilibrium with its environment, which is rarely verified in invasive species, we also conducted further MESS analyses simulating pseudo-equilibrium of $W$. auropunctata distribution with climate, in the geographical region of Israel (Appendix S2).

\section{Genetic analyses}

Using mitochondrial and microsatellite data, we conducted phylogeographical genetic analyses to investigate the branching position of Israeli individuals within a large set of samples from tropical/ 

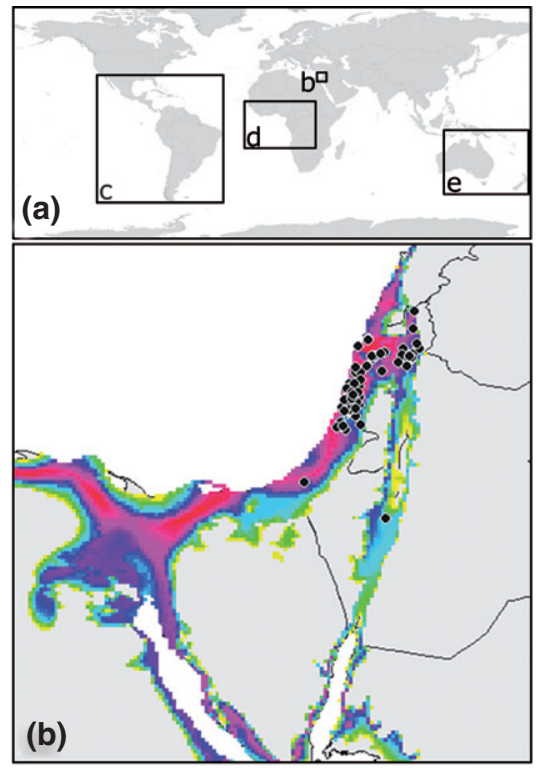


Figure 1 (a) Geographical regions where the DOMAIN model was fitted; (b) in the region of Israel (black circles are $W$. auropunctata distribution records); (c) within the native range and surrounding invaded areas and $(\mathrm{d}-\mathrm{e})$ in regions outside the native range in which invasive $W$. auropunctata populations have been reported (red zones). The colour legend indicated in (c) corresponds to a measure of climatic similarity relative to the niche envelop of $W$. auropunctata defined in Israel based on the Gower metric. The native range of $W$. auropunctata, is surrounded by a green strip in (c). Results of model fitting for the tropical islands of Hawaii and Tahiti, where $W$. auropunctata is established, are not shown because these islands displayed no climatic similarities to Israel.

subtropical native and invasive populations (Figure SS1). DNA was extracted and purified from all individuals analysed, by a standard CTAB (hexadecyltrimethylammonium bromide)-based protocol.

\section{Mitochondrial data}

We amplified a 700-710 bp fragment of the mitochondrial COI (cytochrome oxidase I) gene from 136 individuals (83 workers and 53 queens), with two sets of primers (Appendix S3). In total, 123 of these individuals originated from 31 native and 20 introduced populations in the tropical/subtropical zone; the other 13 individuals (five queens and eight workers) originated from seven nests in Israel (Figure SS1). Two sequences from the closely related species Wasmannia rochai were used as an outgroup.

Our phylogeographical analyses were performed on unique haplotypes (35 in total). Sequences were partitioned into codon positions (cp) and models of evolution were independently selected for five sets of partitions (first cp; second cp; third cp; first/second cp; first/second/third cp). This was achieved by comparing Akaike's information criteria corrected for samples of small size (i.e. AICc, Posada \& Buckley 2004 and references therein) in JMODELTEST (Posada 2008). Relationships between $W$. auropunctata haplotypes were then constructed by Bayesian inference, with MRBAYES v3.1.2 (Ronquist \& Huelsenbeck 2003). Three distinct partitioning strategies (PS) were used (unpartitioned analysis, one partition per $\mathrm{cp}$, one partition for first/second $\mathrm{cp}+$ one partition for third $\mathrm{cp}$ ). For each PS, two independent runs were carried out, for 20 million generations each, with eight Markov chains. The best PS was then identified by comparing Bayes' factors (Kass \& Raftery 1995) and the corresponding tree was constructed with a conservative burn-in of $25 \%$. Node support was estimated from posterior probabilities (i.e. the proportion of post burn-in trees recovering a particular clade; Ronquist \& Huelsenbeck 2003).

More specifically, we evaluated the robustness of the affiliation of the Israeli haplotype to clade B (see results). We constrained the position of the Israeli haplotype by forcing it into the other clade (i.e. clade A), using the settings for the best PS. We then used Bayes' factors to determine whether there was significantly less statistical support for the constrained analysis than for the unconstrained analysis.

\section{Microsatellite data}

In W. auropunctata clonal populations, the nuclear genomes of queens and males behave as two independent lineages (Fournier et al. 2005a; Foucaud et al. 2007). We therefore carried out microsat- 
ellite analyses on the two sexes separately. We added to the data set published by Foucaud et al. (2010) additional data including the genotypes of 12 males and 33 queens from seven populations sampled from Argentina. A global data set of 453 male and 1093 queen genotypes was analysed in this study. For sites from which no males were sampled, we analysed the spermatheca content of the queens, when possible (see Fournier et al. 2005a). All individuals were genotyped at 12 microsatellite loci (Fournier et al. 2005b). Dendrograms were constructed from individual genotypes with the neighbourjoining algorithm (Saitou \& Nei 1987) and a variant of Chakraborty and Jin's allele shared distance (Chakraborty \& Jin 1993; see Fournier et al. 2005a).

\section{Laboratory experiments}

\section{Sampled populations}

We sampled a total of $15 \mathrm{~W}$. auropunctata populations (Table 1). A first set of twelve populations was used to check whether cold adaptation occurred in Israeli populations during invasion: (1) six populations from the native tropical area corresponding to the core habitat, with three populations from natural habitats (i.e. primary forest) and three populations from human-modified habitats (i.e. plantation or roadside) and (2) six populations from the invasive range, two populations from the tropical zone and four populations from the Mediterranean zone (Israel). A second set of three populations was used to determine more specifically the site of adaptation, based on the results of SDM and genetic analyses (see Results): (1) two populations from Zarate (Buenos Aires province, Argentina), a zone located at the southern margin of the native range and (2) one population from Florida, corresponding to a subtropical zone of the introduced range. All but the two Argentinean populations were reared and studied at the CBGP laboratory (Montpellier, France). The two populations from Argentina were reared and studied at the SABCL laboratory (Buenos Aires, Argentina) due to strong legal restrictions on the importation of live $W$. auropunctata from Argentina to Europe. In both laboratories, ants were reared in a walk-in climatic chamber maintained at constant temperature and humidity $\left(25^{\circ} \mathrm{C} ; 70 \% \mathrm{RH}\right.$; L:D $\left.12: 12\right)$ for at least 2 months, to ensure that all the workers tested in the experiments had been produced in the laboratory. This time lag minimised both maternal environmental effects and the impact of the acclimation factor in the interpretation of our results. During this period, ants were fed ad libitum with a honey-yeast-water solution and Ephestia eggs.

\section{Cold tolerance}

We measured survival and time taken by workers to recover from cold stress (a reversible state of narcosis induced by cold). Survival is a direct measure of fitness and time taken to recover from chill coma is an appropriate phenotypic surrogate for the assessment of cold adaptation in insects (Gibert et al. 2001; Hoffmann et al. 2003). All populations were tested according to the same protocol. We placed 50 workers from each population in five sealed and meshed boxes (10 workers per box) and fed them with $0.5 \mathrm{~mL}$ of honeywater for $1 \mathrm{~h}$. Workers were then placed in a climatic chamber at $2{ }^{\circ} \mathrm{C}$ for $16 \mathrm{~h}$. This temperature is close to the lowest absolute minimum air temperature recorded in the winter months between 1981 and 2000 in Tel Aviv (Israel, January: $2.5^{\circ} \mathrm{C}$ and February: $2.6{ }^{\circ} \mathrm{C}$, Israeli Meteorological Service). At the end of the cold-stress period, the boxes were placed in a walk-in climatic chamber with standard
Table 1 Wasmannia auropunctata populations sampled for laboratory experiments assessing cold tolerance. About 20 fertilised queens and 2000-5000 workers per population were sampled

\begin{tabular}{lllll}
\hline Site & Area & Climatic zone & Country & Habitat \\
\hline M11 & Native & Tropical & France (FG) & Natural \\
M3 & Native & Tropical & France (FG) & Natural \\
M7 & Native & Tropical & France (FG) & Natural \\
Cay & Native & Tropical & France (FG) & Human-modified \\
P2 & Native & Tropical & France (FG) & Human-modified \\
Ker & Native & Tropical & France (FG) & Human-modified \\
Mp & Introduced & Tropical & France (NC) & Human-modified \\
Cam & Introduced & Tropical & Cameroon & Human-modified \\
Orl* & Introduced & Subtropical & USA (Florida) & Human-modified \\
Zarate 1* & Margin native & Subtropical & Argentina & Human-modified \\
Zarate 2* & Margin native & Subtropical & Argentina & Human-modified \\
MaAb & Introduced & Mediterranean & Israel & Human-modified \\
NeveUR & Introduced & Mediterranean & Israel & Human-modified \\
NY & Introduced & Mediterranean & Israel & Human-modified \\
$\mathrm{Hz}$ & Introduced & Mediterranean & Israel & Human-modified \\
\hline
\end{tabular}

Country code $\mathrm{FG}=$ French Guiana; $\mathrm{NC}=\mathrm{New}$ Caledonia. See main text ('materials and methods' section) for further details on different types of areas. * indicates populations more specifically used to verify the site of cold adaptation, based on the results of the SDM and genetic analyses (see Figs 1, 2 and 3)

climatic conditions (i.e. $25{ }^{\circ} \mathrm{C}, 70 \% \mathrm{RH}$ ). The proportion of workers recovering from cold stress in each box was determined at 11 time points: just after the cold shock, after 27, 40 and $60 \mathrm{~min}$, and then every $30 \mathrm{~min}$ until $5 \mathrm{~h}$. This experiment was then repeated for all but the two Argentinean populations tested, giving a total of 1400 tested workers $(50$ workers $\times 13$ populations $\times 2$ runs at the CBGP and 50 workers $\times 2$ populations at the SABCL).

We investigated the response of workers to cold stress as a function of six biogeographical origins defined on the basis of the following three criteria: native vs. introduced, climatic range (tropical, subtropical or Mediterranean), and natural vs. human-modified habitats. As not all population combinations exist in the field (e.g. introduced populations in natural habitats) we ended up with six biogeographical origins: tropical native area in natural habitat, tropical native area in human-modified habitat, tropical-introduced zone, subtropical introduced zone (i.e. Florida), subtropical native marginal zone (i.e. Argentina) and Mediterranean-introduced area (i.e. Israel). For each of these six origins, we investigated the relationship between the proportion of workers that had recovered and the time since cold stress, by fitting a non-linear mixed model (nlme) according to a reparameterised Gompertz relationship implemented using R statistical software (R Development Core Team 2010), with a mean function defined as follows:

$\mathrm{f}(x)=$ platean $* \exp (-\exp (c *(d-x)))$

This model was found to better fit the pattern of worker recovery following cold stress over the period of observation than a linear model for the six biogeographical origins (Appendix S4). Two parameters, the 'plateau' and the parameter ' $d$, corresponding to the maximum proportion of surviving workers and the abscissa at the inflexion point (i.e. a good proxy for the speed with which workers recovered), respectively, were estimated for each of the six biogeographical origins and compared. Parameter estimates with non-overlapping confidence intervals were considered to be significantly different. Note that the estimate of 'time for workers to recover' obtained for the Argentinean populations should be interpreted 
carefully as the experiment on these populations was conducted independently in a different laboratory.

We also conducted complementary analyses based on general linear mixed models (GLMM), using both the maximal proportion of surviving workers and the time taken to reach half the maximal proportion of recovered workers as response variables (Appendix S5).

\section{RESULTS}

\section{Species distribution modelling}

The climatic envelope modelled on the basis of the occurrences of $W$. auropunctata nests in Israel accurately predicted the presence of $W$. auropunctata nests throughout this geographical region (Fig. 1b; AUC $=0.95$ ). Our predictive analyses across the global distribution range of $W$. auropunctata highlighted a small number of regions with climatic conditions similar, in terms of coldness, to those occupied by $W$. auropunctata in Israel. We identified the north-eastern region of Argentina as the largest geographical region with similarities to the climatic envelope defined in Israel within the native range and the surrounding regions of this species (Fig. 1c). Outside its native range, some regions of North America, Australia and Africa also displayed locally similar cold temperatures (Fig. 1c-e). However, Florida was the only such region in which populations of $W$. auropunctata were reported. This species indeed occurs in Africa and Australia, but not under local climate conditions, in term of coldness, similar to those found in Israel (Fig. 1d-e). Similar results were obtained using the MESS approach (Appendix S1) as well as when considering pseudo-equilibrium of $W$. auropunctata distribution records with climate (Appendix S2).

\section{Genetic analyses}

Our tree based on the mitochondrial COI contains two main clades: clades A and B (Fig. 2; see also Mikheyev \& Mueller 2007). All the populations established in Israel were characterised by a unique haplotype branching off within clade B. The alternative topology (i.e. Israeli haplotype constrained into clade A) was less supported than the best topology obtained (Bayes' factor $=5.1$ ). Clade B contains other populations located in the southern region of the native range (i.e. haplotypes from North Argentina, Paraguay and southern Brazil).The Israeli haplotype was rigorously identical to that found in clonal populations established in Zárate, Buenos Aires province (Argentina C5, Fig. 2 and see map in Appendix SF1) and differed from the haplotype of the clonal lineage established in the city of Buenos Aires by only one nucleotide (Argentina C4, Appendix SF1). The Florida haplotype was assigned to clade A, indicating that the Florida and Israeli populations are genetically well differentiated.

The microsatellite data obtained for queens and males confirmed that Israeli populations were established from a single pair of queen and male genotypes reproducing clonally. These clonal genotypes were strictly identical to those found by Vonshak et al. (2009) in samples collected in 2005. Both the queen and male genotypes from Israel were assigned to genetic clusters including only genotypes of individuals from Argentina (Fig. 3). For queens, the closest Argentinean genotypes were those of individuals from populations established near Buenos Aires and in the Ocloyas mountain region (C4, C5 and C3; Fig. 3; Figure SS1). The Israeli clonal male lineage had a multilocus haploid genotype remarkably similar to that of clonal males from Argentinean populations established near Buenos Aires (C5 and C6; Fig. 3). Consistent with phylogeographical results based on mtDNA analyses, the Israeli queen and male microsatellite genotypes were distantly related to those of populations from Florida (Fig. 3).

\section{Cold tolerance}

Workers from populations established in Israel survived significantly better (plateau $=0.95)$ and recovered faster $(d=35.67)$ than workers from the tropical native area of both natural habitats (platean $=0.15$; $d=59.01$ ) and human-modified habitats (platean $=0.35 ; d=52.86$ ) and populations established in the tropical-introduced zone (plateau $=0.46 ; d=74.95$ ) (Fig. 4b). Workers from the subtropicalintroduced zone, (Florida; platean $=0.79 ; d=62.83$ ) and from the subtropical native marginal zone (Argentina; plateau $=0.91$; $d=7.24)$ also recovered better and faster than all tropical populations. Workers from Israeli populations survived better and recovered faster than populations originating from Florida, but did not do better than Argentinean populations.

Additional analyses based on GLMMs revealed similar trends and led to the same main conclusions (Appendix S5).

\section{DISCUSSION}

\section{Evidence for evolutionary changes during invasion}

Physiological adaptations to particular climatic conditions during invasion have been demonstrated in various plant species (e.g. Blair \& Wolfe 2004; Dlugosch \& Parker 2008). However, there is little empirical evidence of such adaptation in animals (but see Huey et al. 2000; Lee et al. 2011). Our study thus provides one of the few empirical demonstrations that adaptive changes to a physiological trait, cold tolerance in this case, may also lead to the establishment and facilitate invasion by animal populations. Adaptation to cold allows $W$. auropunctata workers to continue foraging throughout the year, even in the winter conditions of the Mediterranean climate of Israel, which is harsher than that of the tropical zone. Associated with invasive traits characterising all clonal populations (e.g. ecological dominance), tolerance to cold temperatures thus constitutes a key evolutionary shift crucial for the invasion of $W$. auropunctata populations established in this region.

Phenotypic differentiation between the invasive and native populations may also result from stochastic evolutionary change rather than adaptive changes in response to particular selection pressures (Keller \& Taylor 2008). However, this seems unlikely in the case of the invasive Mediterranean populations of $W$. auropunctata. Indeed, our results indicate that cold tolerance, albeit of lower intensity, has emerged independently in a genetically different invasive population established in another remote geographical region (i.e. Florida), in response to similar cold selection pressure.

\section{When and where do evolutionary changes occur during invasion processes?}

This multidisciplinary approach showed that Israeli populations followed a prior-adaptation invasion scenario, with adaptation to cold occurring before long-distance dispersal to Israel in popula- 




W. rochai (EF459822, EF459824)

$\underline{0.1}$

Figure 2 Consensus tree for the phylogeographical analyses based on mtDNA haplotypes. Posterior probabilities of nodes are shown for values $>50 \%$. For each shared haplotype, the name of the sampled population is provided and the number of individuals sequenced per population is indicated in brackets. The Argentinean haplotypes are shown in bold characters, the Florida haplotype is shown in bold italic characters and the Israeli haplotype is shown in underlined bold characters. See figure SS1 in supplementary information for site names and locations. The closely related species Wasmannia rochai (GenBank accession numbers EF459732 - EF759824) was used as an outgroup.

tions located at the southern margin of the native distribution of the species (i.e. northern Argentina). Israeli populations are genetically similar to populations in northern Argentina, the latter facing with similar cold selection pressure and displaying similar cold adaptation. On the contrary, the post-introduction adaptation scenario is unlikely in the case of W.auropunctata Israeli populations. Indeed, Israeli populations are characterised by only a single couple of queen and male clonal genotypes most probably originating from the same Argentinean population. Moreover, we found no evidence of admixture and/or mutation/recombination events in the microsatellite multilocus genotypes of reproductives from Israeli populations compared to those sampled 5 years before by Vonshak et al. (2009). In the same way, the bridgehead scenario is also unlikely to explain the invasion of $W$. auropunctata in Israel. The unique cold-tolerant population identified that could have serve as a bridgehead population for subsequent establishment in Israel, i.e. Florida, was found to be genetically distinct from the Israeli population. 


\section{(a) (Queens)}

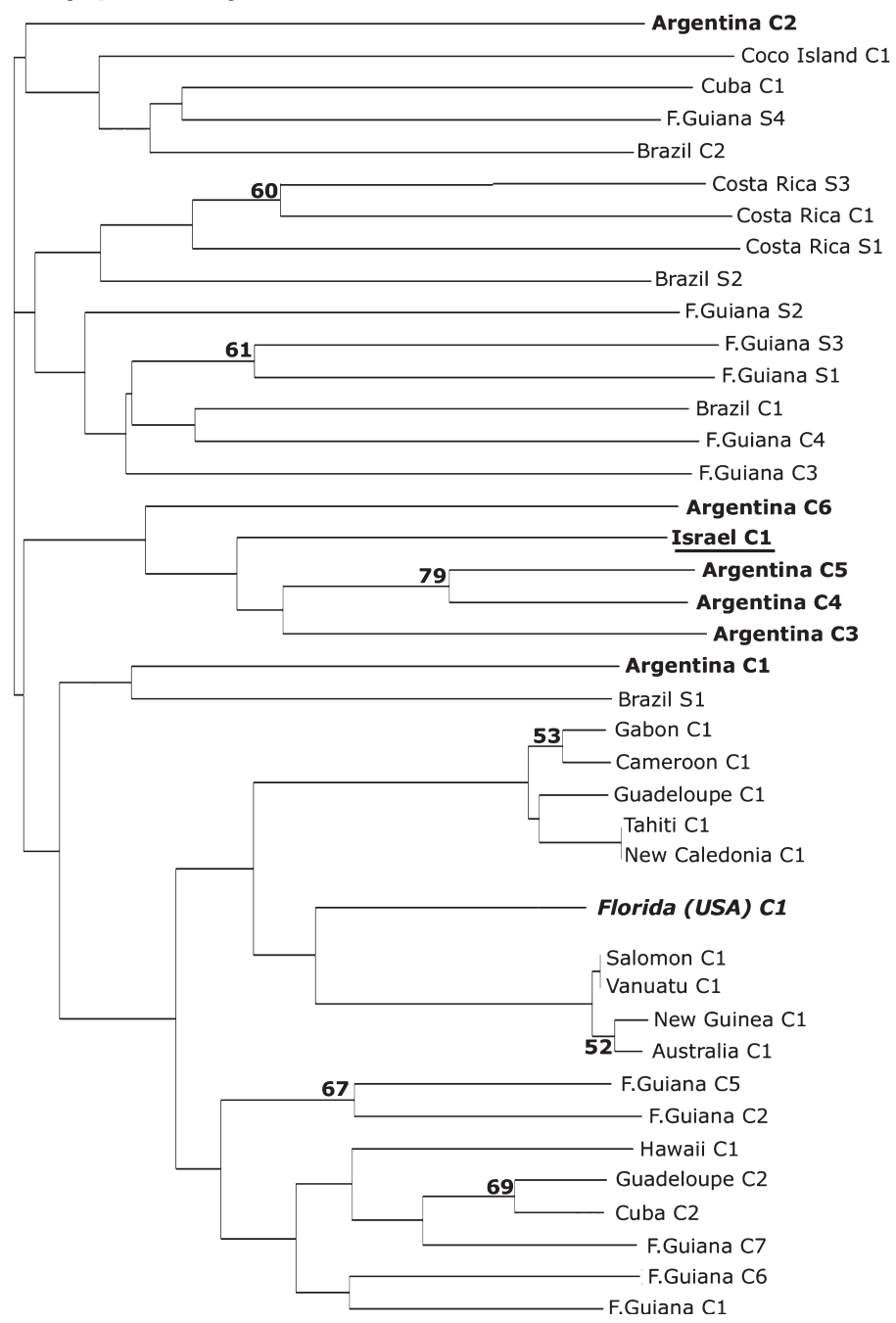

(b) (Males)

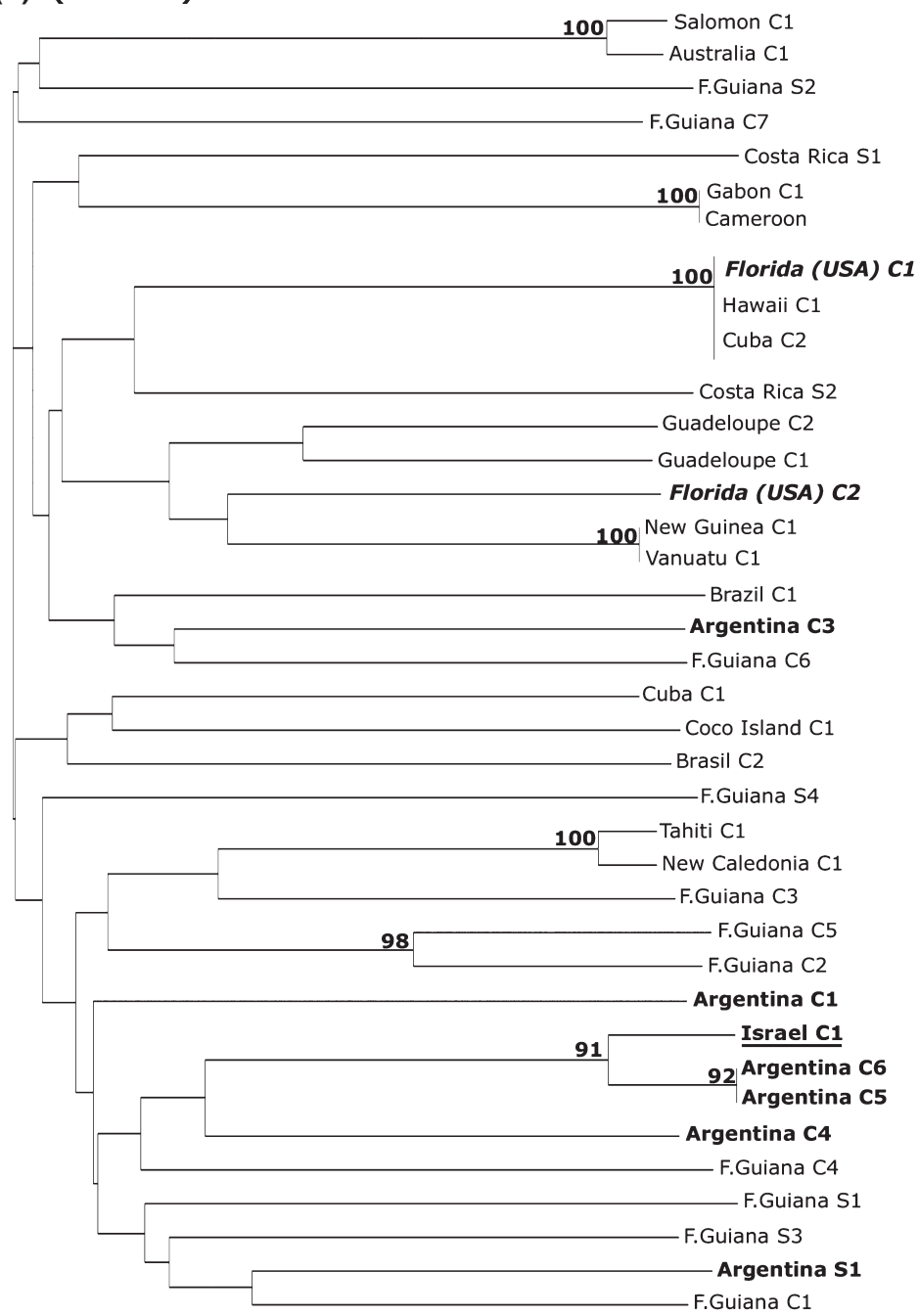

Figure $3 \mathrm{NJ}$ dendrograms of the microsatellite allele shared distances between individual queens (a) and males (b). The Argentinean genotypes are shown in bold characters, the Florida genotypes are shown in bold italic characters and the Israeli genotype is shown in underlined bold characters. Dendrograms are not rooted, due to the lack of PCR amplification for many $W$. auropunctata microsatellite loci in the closely related species $W$. rochai used as an outgroup in Fig. 2. Bootstrap values (computed from 1000 replicates) for nodes are shown only when $>50 \%$. Note that low bootstrap values (bootstrapping over loci) are usually obtained for trees with individuals as tips.

The nature of the evolutionary change (i.e. adaptive vs. stochastic) that has led to cold-tolerance in Argentinean populations, hence, promoting the establishment and the invasion of at least one invasive propagule in Israel, could not be unravelled precisely. Further statistical analyses similar to those implemented by Keller et al. (2009), conducted on a sufficiently large number of populations established in Argentina might be useful to clarify this point. However, because cold tolerance emerged two times independently in genetically distinct lineages established in a Mediterranean-like climate (i.e. Argentina/Israel and Florida), the most parsimonious hypothesis is that cold tolerance resulted from adaptive changes. Interestingly, Florida most probably followed a scenario of invasion different from the prior-adaption scenario. Although this scenario cannot be determined with the present data, this study supports the view that the invasion of a new environment may be achieved through different eco-evolutionary scenarios even at the intraspecific level.
A role for prior adaptation within or at the margin of a species' native range in the invasion of remote locations by some populations has been suggested in previous studies (e.g. Elton 1958), but little convincing evidence for this scenario has been obtained. Our study is, to our knowledge, the first to demonstrate it unambiguously. Consistent with this scenario, the limits of the native ranges of organisms are often viewed as zones of habitat differentiation and heterogeneity, in which diverse evolutionary processes may occur (Kirkpatrick \& Barton 1997; Thomas et al. 2001). Furthermore, the potential to evolve in response to new conditions is likely to be greater within or at the edge of the native range than in the introduced range, due to larger effective population sizes, genetic variation and propagule pressure over evolutionary time scales (Hufbauer et al. 2012).

This study challenges the noteworthy small proportion of prioradaptation suggested in the literature relative to the post-introduction invasion scenario (but see Bossdorf et al. 2008). The scarcity of 


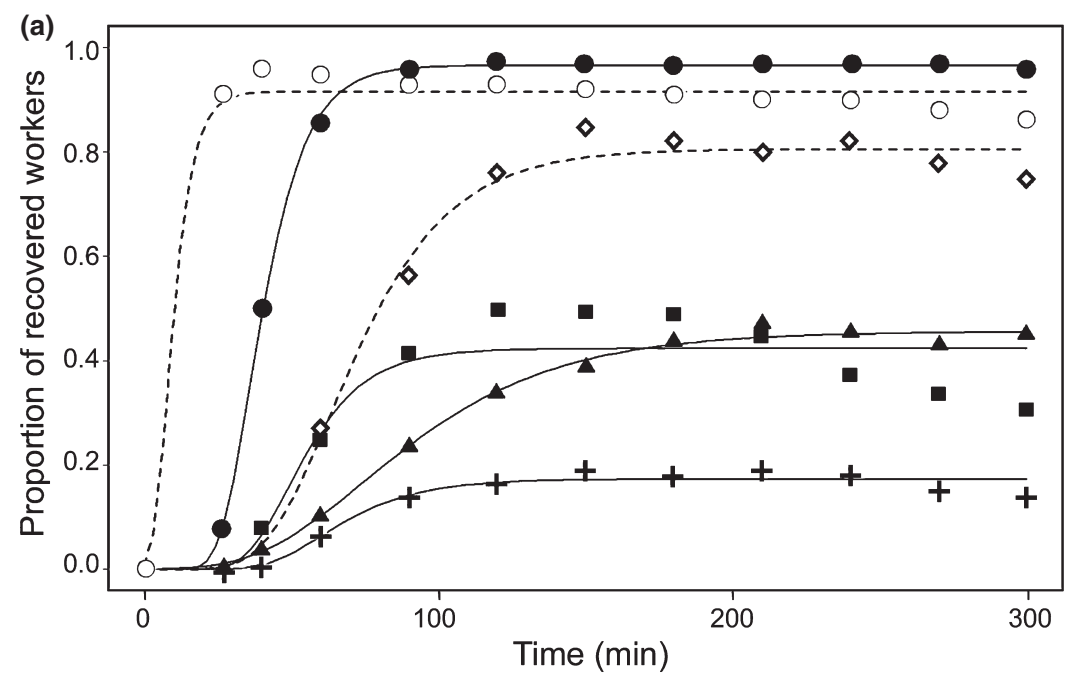

(b)
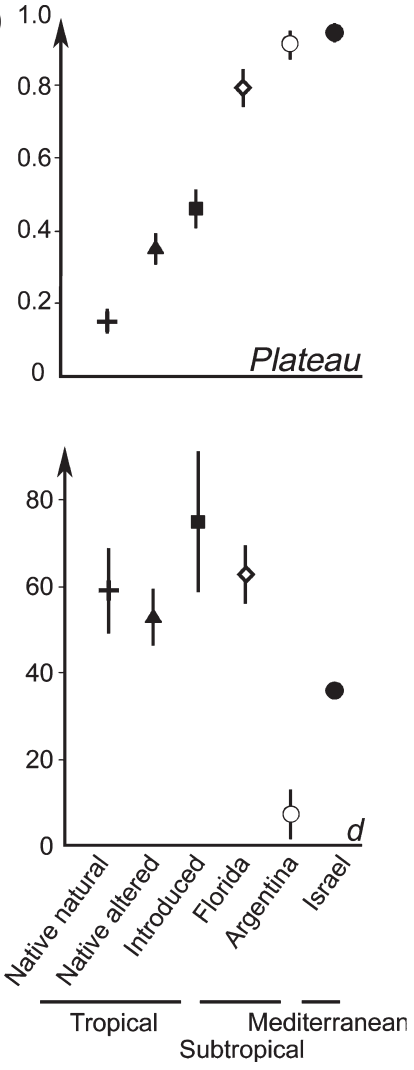

Figure 4 (a) Fits of non-linear mixed models using Gompertz functions for the proportion of workers recovering at each observation time for each of the six biogeographical areas. (b) Comparison of Gompertz function parameters estimated for each biogeographical area, for the parameter plateau at the top, and parameter $d$ at the bottom (see text for details). Closed symbols correspond to populations used to test whether adaptation occurred in the Mediterranean populations compared to populations established in the core habitat of the native range. Open symbols correspond to the populations used for more specifically studying the location at which cold adaptation occurred, based on the results obtained in SDM and genetic analyses (see Figs 1, 2 and 3).

empirical studies unambiguously illustrating the prior adaptation invasion scenario may reflect a lack of informative data (Hufbauer et al. 2012). More integrative studies, such as that described here, are required to improve our knowledge of the eco-evolutionary scenarios underlying invasions. A frequent association of prior adaptation with invasion in remote locations would provide further evidence against the apparent paradox of invasion that some populations characterised by low levels of adaptive genetic diversity are able to adapt to local abiotic conditions in a new habitat (Allendorf \& Lundquist 2003).

\section{Benefits of a multidisciplinary approach for determining eco-evolutionary scenarios of invasion}

Many studies have reported phenotypic divergence between native and invasive populations (e.g. Blair \& Wolfe 2004; Bossdorf et al. 2008), but only a few have carried out genetic analyses to determine the exact source of invasive populations (but see Xu et al. 2010). This limitation is generally overcome by the comparison of numerous samples of native and invasive populations, assuming that the sampled populations broadly reflect the entire niche of the species (Dlugosch \& Parker 2008). However, in the absence of precise knowledge about the genotypes introduced, patterns of adaptive change within invasive populations must be interpreted with caution, because the use of this approach alone may result in erroneous conclusions. In the case of $W$. auropunctata, a comparison of the Mediterranean invasive populations with arbitrarily sampled tropical native populations might have led to the conclusion that adaptation to cold occurred locally after introduction (i.e. following a postintroduction adaptation scenario).

Genetic approaches are useful for (1) tracing the route of invasion and, hence, for identifying source populations and (2) highlighting demographic events associated with invasion processes (see Estoup \& Guillemaud 2010 for review). However, genetic tools provide no information about whether invasive populations face new selection pressures and whether evolutionary changes occur during the invasion process. For example, Ascunce et al. (2011) used genetic approaches to demonstrate that invasive populations of the fire ant, Solenopsis invicta, established in Florida behaved as source populations from which propagules dispersed and established new populations in remote locations, such as New Zealand and China. However, it remains unknown whether invasion in these remote locations is associated with key evolutionary changes within Florida following a bridgehead scenario. In $W$. auropunctata, the use of genetic approaches alone would have led to the identification of the Argentinean populations as the source of invasive populations established in the Mediterranean region, but would not have provided any information about the adaptive changes underlying the invasion of these populations.

Finally, the species distribution models initially used to predict the biogeographical invasion potential of some species (Peterson 
2003) have recently been used to determine whether and where climate niche shifts occur during invasion (e.g. Broennimann et al. 2007; Angetter et al. 2011). These approaches may provide information about whether invasive populations face new selection pressures likely to promote adaptive changes. For instance, Fitzpatrick et al. (2007) suggested that some populations of S. invicta originating from the southern margin of the native range of the species invaded certain sites in the United States at which climatic conditions were similar to those of the native range, subsequently colonising colder environments within the introduced range. However, these authors neither identified the source populations giving rise to the invasive populations, nor investigated whether and where potential adaptive changes occurred during the invasion processes. In $W$. auropunctata, the use of SDM approaches would have suggested that populations established in the Mediterranean zone (i.e. Israel) probably originated from already adapted populations established in Argentina (i.e. margin prior-adaptation scenario) or Florida (i.e. bridgehead scenario), but would not have made it possible to distinguish between these two origins.

\section{CONCLUSION}

Determining whether and where adaptive changes occur during invasion is challenging. As first suggested by Hufbauer et al. (2012) and demonstrated here, several complementary approaches are required. We propose an efficient and general methodological procedure for focusing more directly on the key populations to be studied, to decipher unambiguously the eco-evolutionary invasion scenario. First, it is important to identify particular selection pressures within the invasive range that may have induced adaptive changes to a given phenotypic trait in the introduced populations. Species distribution models can then be used to identify possible sites at which native and introduced populations face similar selection pressures. With the increasing use of SDM approaches in biology, the available data sets will undoubtedly become increasingly appropriate for addressing questions relating to biological invasions, including adaptation to biotic features (i.e. biotic interactions). Second, genetic approaches are crucial for tracing the route of invasions and identifying the source populations giving rise to invasive populations. Population sampling for genetic analyses should focus specifically on populations established within the geographical regions identified by SDM, although other population samples are also required for the analysis. Ultimately, phenotypic analyses are required to determine whether adaptive changes occur during the invasion process. These analyses should be designed so as to include populations established in the native core habitat of the species and populations identified as the potential source population of the targeted invasive population in genetic and SDM analyses. We believe that serial processing via these three steps is crucial to determine unequivocally the eco-evolutionary invasion scenario. We hope that this study will inspire future research on invasive species from other taxa, thus improving general knowledge concerning biological invasion processes.

\section{ACKNOWLEDGEMENTS}

We would like to thank R. Federman for providing GPS coordinates for $W$. auropunctata nests in Israel, available from the website of the Israeli Environmental Protection Ministry (in Hebrew). We would also like to thank G. Morton for providing the population from Australia. We thank C. Coulin, who helped to conduct coldtolerance experiments at the SABCL laboratory (Buenos Aires, Argentina). Finally, we thank V. Ravigné for comments and discussion. This work was supported by grants from the French Ministère de l'Ecologie et du Développement Durable (ECOTROP programme) awarded to AE and JO and from the French Agropolis foundation (RTRA- Montpellier, BIOFIS project 1001-001) to AE, JPR and $\mathrm{BF}$. Some of the data analysed here, including the genetic data in particular, were generated at the molecular genetic analysis technical facilities of the Environment and Biodiversity IFR 119 at Montpellier (France).

\section{AUTHORS' CONTRIBUTIONS}

$\mathrm{OR}, \mathrm{AE}, \mathrm{JF}$ and $\mathrm{BF}$ conceived the study; $\mathrm{OR}, \mathrm{AE}$ and $\mathrm{BF}$ wrote the manuscript; $\mathrm{OR}, \mathrm{AL}, \mathrm{AE}, \mathrm{BF}$ performed the main laboratory experiment and LC performed the laboratory experiment on Argentinean populations; OR, JF and AL produced the genetic data; OR, $\mathrm{AE}$ and $\mathrm{BF}$ processed the data, with assistance from $\mathrm{SB}, \mathrm{JPR}$ and GJK for statistical analyses, the development of species distribution models and genetic analyses, respectively; OR, AE, MV, AL, JF, JO, LC, LC, ML and TS collected samples.

\section{REFERENCES}

Allendorf, F.W. \& Lundquist, L.L. (2003). Introduction: population biology, evolution, and control of invasive species. Cons. Biol., 17, 24-30.

Angetter, L.S., Lotters, S. \& Rodder, D. (2011). Climate niche shift in invasive species: the case of the brown anole. Biol. J. Linn. Soc., 104, 943-954.

Ascunce, M.S., Yang, C.C., Oakey, J., Calcaterra, L., Wu, W.J., Shih, C.J. et al. (2011). Global invasion history of the fire ant Solenopsis invicta. Science, 331, 1066-1068.

Bivand, R. (2011). (software) spgrass6: interface between GRASS 6 and R. R package version $0.6-27$.

Blair, A.C. \& Wolfe, L.M. (2004). The evolution of an invasive plant: an experimental study with Silene latifolia. Ecology, 85, 3035-3042.

Bossdorf, O., Lipowsky, A. \& Prati, D. (2008). Selection of preadapted populations allowed Senecio inaequidens to invade Central Europe. Divers. Distrib., 14, 676-685.

Broennimann, O., Treier, U.A., Muller-Scharer, H., Thuiller, W., Peterson, A.T. \& Guisan, A. (2007). Evidence of climatic niche shift during biological invasion. Ecol. Lett., 10, 701-709.

Carpenter, G., Gillison, A.N. \& Winter, J. (1993). Domain - a flexible modelling procedure for mapping potential distributions of plants and animals. Biodivers. Conserv., 2, 667-680.

Chakraborty, R. \& Jin, L. (1993). Determination of relatedness between individuals using DNA-fingerprinting. Hum. Biol., 65, 875-895.

Cox, G.W. (2004). Alien Species and Evolution. The Evolutionary Ecology of Exotic Plants, Animals, Microbes, and Interacting Native Species. Island Press, Washington (USA), p. 377

Dlugosch, K.M. \& Parker, I.M. (2008). Invading populations of an ornamental shrub show rapid life history evolution despite genetic bottlenecks. Ecol. Lett., 11, 701-709.

Elith, J., Kearney, M. \& Phillips, S. (2010). The art of modelling range-shifting species. Met. Ecol. Evol., 1, 330-342.

Elton, C.S. (1958). The Ecology of Invasions by Animals and Plants. Chapman and Hall, London.

Estoup, A. \& Guillemaud, T. (2010). Reconstructing routes of invasion using genetic data: why, how and so what? Mol. Ecol., 19, 4113-4130.

Fielding, A.H. \& Bell, J.F. (1997). A review of methods for the assessment of prediction errors in conservation presence/absence models. Environ. Conserv., 24, 38-49. 
Fitzpatrick, M.C., Weltzin, J.F., Sanders, N.J. \& Dunn, R.R. (2007). The biogeography of prediction error: why does the introduced range of the fire ant over-predict its native range? Global. Ecol. Biogeogr., 16, 24-33.

Foucaud, J., Fournier, D., Orivel, J., Delabie, J.H.C., Loiseau, A., Le Breton, J. et al. (2007). Sex and clonality in the little fire ant. Mol. Biol. Evol., 24, 24652473.

Foucaud, J., Orivel, J., Fournier, D., Delabie, J.H.C., Loiseau, A., Le Breton, J. et al. (2009). Reproductive system, social organization, human disturbance and ecological dominance in native populations of the little fire ant, Wasmannia auropunctata. Mol. Ecol., 18, 5059-5073.

Foucaud, J., Orivel, J., Loiseau, A., Delabie, J.H.C., Jourdan, H., Konghouleux, D. et al. (2010). Worldwide invasion by the little fire ant: routes of introduction and eco-evolutionary pathways. Evol. Appl., 3, 363-374.

Fournier, D., Estoup, A., Orivel, J., Foucaud, J., Jourdan, H., Le Breton, J. et al. (2005a). Clonal reproduction by males and females in the little fire ant. Nature, 435, 1230-1235.

Fournier, D., Foucaud, J., Loiseau, A., Cros-Arteil, S., Jourdan, H., Orivel, J. et al. (2005b). Characterization and PCR multiplexing of polymorphic microsatellite loci for the invasive ant Wasmannia auropunctata. Mol. Ecol. Notes, $5,239-242$

Gibert, P., Moreteau, B., Petavy, G., Karan, D. \& David, J.R. (2001). Chill-coma tolerance, a major climatic adaptation among Drosophila species. Evolution, 55, 1063-1068.

Hijmans, R.J. \& van Etten, J. (2010). raster: Geographic analysis and modeling with raster data. $\mathrm{R}$ package version 1.9-58. Available at: http://CRAN.Rproject.org/package $=$ raster. Last accessed 8 August 2012.

Hijmans, R.J., Cameron, S.E., Parra, J.L., Jones, P.G. \& Jarvis, A. (2005). Very high resolution interpolated climate surfaces for global land areas. Int. J. Climatol., 25, 1965-1978.

Hijmans, R.J., Phillips, S., Leathwick, J. \& Elith, J. (2010). dismo: Species distribution modeling. $\mathrm{R}$ package version 0.7-17. Available at: http://CRAN. R-project.org/package $=$ dismo. Last accessed 8 August 2012.

Hoffmann, A.A., Sorensen, J.G. \& Loeschcke, V. (2003). Adaptation of Drosophila to temperature extremes: bringing together quantitative and molecular approaches. J. Therm. Biol., 28, 175-216.

Huey, R.B., Gilchrist, G.W., Carlson, M.L., Berrigan, D. \& Serra, L. (2000). Rapid evolution of a geographic cline in size in an introduced fly. Science, 287, 308-309.

Hufbauer, R.A., Facon, B., Ravigné, V., Turgeon, J., Foucaud, J., Lee, C. et al. (2012). Anthropogenically-Induced Adaptation to Invade (AIAI): contemporary adaptation to human-altered habitats within the native range can promote invasions. Evol. Appl., 5, 89-101. DOI: 10.1111/j.17524571.2011.00211.x

Kass, R.E. \& Raftery, A.E. (1995). Bayes factors. J. Am. Stat. Assoc., 90, 773-795.

Keller, S.R. \& Taylor, D.R. (2008). History, chance and adaptation during biological invasion: separating stochastic phenotypic evolution from response to selection. Ecol. Lett., 11, 852-866.

Keller, S.R., Sowell, D.R., Neiman, M., Wolfe, L.M. \& Taylor, D.R. (2009). Adaptation and colonization history affect the evolution of clines in two introduced species. New Phytol., 183, 678-690.

Kirkpatrick, M. \& Barton, N.H. (1997). Evolution of a species' range. Am. Nat., $150,1-23$

Lachmuth, S., Durka, W. \& Schurr, F.M. (2010). The making of a rapid plant invader: genetic diversity and differentiation in the native and invaded range of Senecio inaequidens. Mol. Ecol., 19, 3952-3967.

Lee, C.E. (1999). Rapid and repeated invasions of fresh water by the copepod Eurytemora affinis. Evolution, 53, 1423-1434.

Lee, C.E., Kiergaard, M., Gelembiuk, G.W., Eads, B.D. \& Posavi, M. (2011). Pumping ions: rapid parallel evolution of ionic regulation following habitat invasions. Evolution, 65, 2229-2244.
Lombaert, E., Guillemaud, T., Cornuet, J.M., Malausa, T., Facon, B. \& Estoup, A. (2010). Bridgehead effect in the worldwide invasion of the biocontrol harlequin ladybird. PLOS ONE, 5, e9743.

Mikheyev, A.S. \& Mueller, U.G. (2007). Genetic relationships between native and introduced populations of the little fire ant Wasmannia auropunctata. Divers. Distrib., 13, 573-579.

Orivel, J., Grangier, J., Foucaud, J., Le Breton, J., Andrès, F.X., Jourdan, H. et al. (2009). Ecologically heterogeneous populations of the invasive ant Wasmannia auropunctata within its native and introduced ranges. Ecol. Entomol., 34, 504-512.

Peterson, A.T. (2003). Predicting the geography of species' invasions via ecological niche modelling. Q. Rev. Biol., 78, 419-433.

Posada, D. (2008). jModelTest: phylogenetic model averaging. Mol. Biol. Evol., 25, 1253-1256.

Posada, D. \& Buckley, T.R. (2004). Model selection and model averaging in phylogenetics: advantages of Akaike information criterion and Bayesian approaches over likelihood ratio tests. Syst. Biol., 53, 793-808.

Ronquist, F. \& Huelsenbeck, J.P. (2003). MrBayes 3: Bayesian phylogenetic inference under mixed models. Bioinformatics, 19, 1572-1574.

Saitou, N. \& Nei, M. (1987). The neighbor-joining method - a new method for reconstructing phylogenetic trees. Mol. Biol. Evol., 4, 406-425.

Sakai, A.K., Allendorf, F.W., Holt, J.S., Lodge, D.M., Molofsky, J., With, K.A. et al. (2001). The population biology of invasive species. Annu. Rev. Ecol. Syst., 32, 305-332.

Thomas, C.D., Bodsworth, E.J., Wilson, R.J., Simmons, A.D., Davies, Z.G., Musche, M. et al. (2001). Ecological and evolutionary processes at expanding range margins. Nature, 411, 577-581.

Vonshak, M., Dayan, T., Foucaud, J., Estoup, A. \& Hefetz, A. (2009). The interplay between genetic and environmental effects on colony insularity in the clonal invasive little fire ant Wasmannia auropunctata. Behav. Ecol. Sociobiol., 63, 1667-1677.

Vonshak, M., Dayan, T., Ionescu-Hirsh, A., Freidberg, A. \& Hefetz, A. (2010). The little fire ant Wasmannia auropunctata: a new invasive species in the middle east and its impact on the local arthropod fauna. Biol. Inv., 12, 1825-1837.

Wetterer, J.K. \& Porter, S.D. (2003). The little fire ant, Wasmannia auropunctata: distribution, impact, and control. Sociobiology, 42, 1-41.

Xu, C.Y., Julien, M.H., Fatemi, M., Girod, C., Van Klinken, R.D., Gross, C.L. et al. (2010). Phenotypic divergence during the invasion of Phyla canescens in Australia and France: evidence for selection-driven evolution. Ecol. Lett., 13, $32-44$.

\section{SUPPORTING INFORMATION}

Additional Supporting Information may be downloaded via the online version of this article at Wiley Online Library (www.ecologyletters.com).

As a service to our authors and readers, this journal provides supporting information supplied by the authors. Such materials are peer-reviewed and may be re-organised for online delivery, but are not copy-edited or typeset. Technical support issues arising from supporting information (other than missing files) should be addressed to the authors.

Editor, Hector Arita

Manuscript received 1 March 2012

First decision made 29 March 2012

Second decision made 29 June 2012

Manuscript accepted 17 July 2012 
Appendix S1: Projection of the climatic envelop modeled from 88 distribution records of $W$. auropunctata in Israel (see figure 1B in the main text), in South and Central America according to the multivariate environmental similarity surface approach (MESS) developed by Elith et al. (2010).

The MESS analysis was performed using MAXENT (Phillips et al. 2006).

The color legend corresponds to the MESS index showing similarity (positive values with higher degree of similarity ranging from green to blue colours) and dissimilarity (negative values with lower degree of similarity from green to yellow colours). Regions in white correspond to regions with MESS values lower than -250, i.e. showing a high degree of dissimilarity with the climatic envelop modeled from 88 distribution records of $W$. auropunctata in Israel. 




Results: According to the MESS analysis, the North-Eastern region of Argentina and Florida display climatic characteristics, in terms of coldness, similar to those of the locations at which W. auropunctata occurs in Israel. To a lower extent, other regions of Mexico and South USA also display locally similar cold temperatures according to the MESS analysis. Yet, no $W$. auropunctata occurrences are known in these regions.

\section{$\underline{\text { References: }}$}

Phillips, S. J., Anderson, R. P., Schapire, R. E. 2006. Maximum entropy modeling of species geographic distributions. Ecol. Model. 190:3-4, 231-259. 
Appendix S2: Projection of the climatic envelop modeled from A) urban areas and populated places in the geographic region of Israel and B) the entire geographic region of Israel (the geographic region defined in the main text, see Figure 1B), in South and Central America according to the multivariate environmental similarity surface approach (MESS) developed by Elith et al. (2010). The MESS analysis was performed using MAXENT (Phillips et al. 2006).

These analyses allowed simulating a situation of pseudo-equilibrium of $W$. auropunctata distribution with regards to climate in Israel. The first criterion (i.e. urban areas and populated places) was first adopted because $W$. auropunctata is known to be intimately associated with human-modified habitats in its area of introduction, particularly in Israel (Vonshak et al. 2009). The land-use information allowing defining urban areas and populated places was obtained from the Natural Earth website: http://www.naturalearthdata.com/). The second criterion (overall the geographic region of Israel) was adopted to simulate an extreme (most likely largely overestimated) situation of equilibrium where W. auropunctata is able to settle in the entire geographic region of Israel.

The color legend corresponds to the MESS index showing similarity (positive values with higher degree of similarity ranging from blue to red colours) and dissimilarity (negative values with lower degree of similarity ranging from blue to yellow colours), with the climatic envelop modelled from A) all urban areas and populated places in Israel and B) the entire geographic region of Israel.

Both climatic envelops were projected worldwide and lead to conclusions similar to those found in the manuscript (data not shown). 


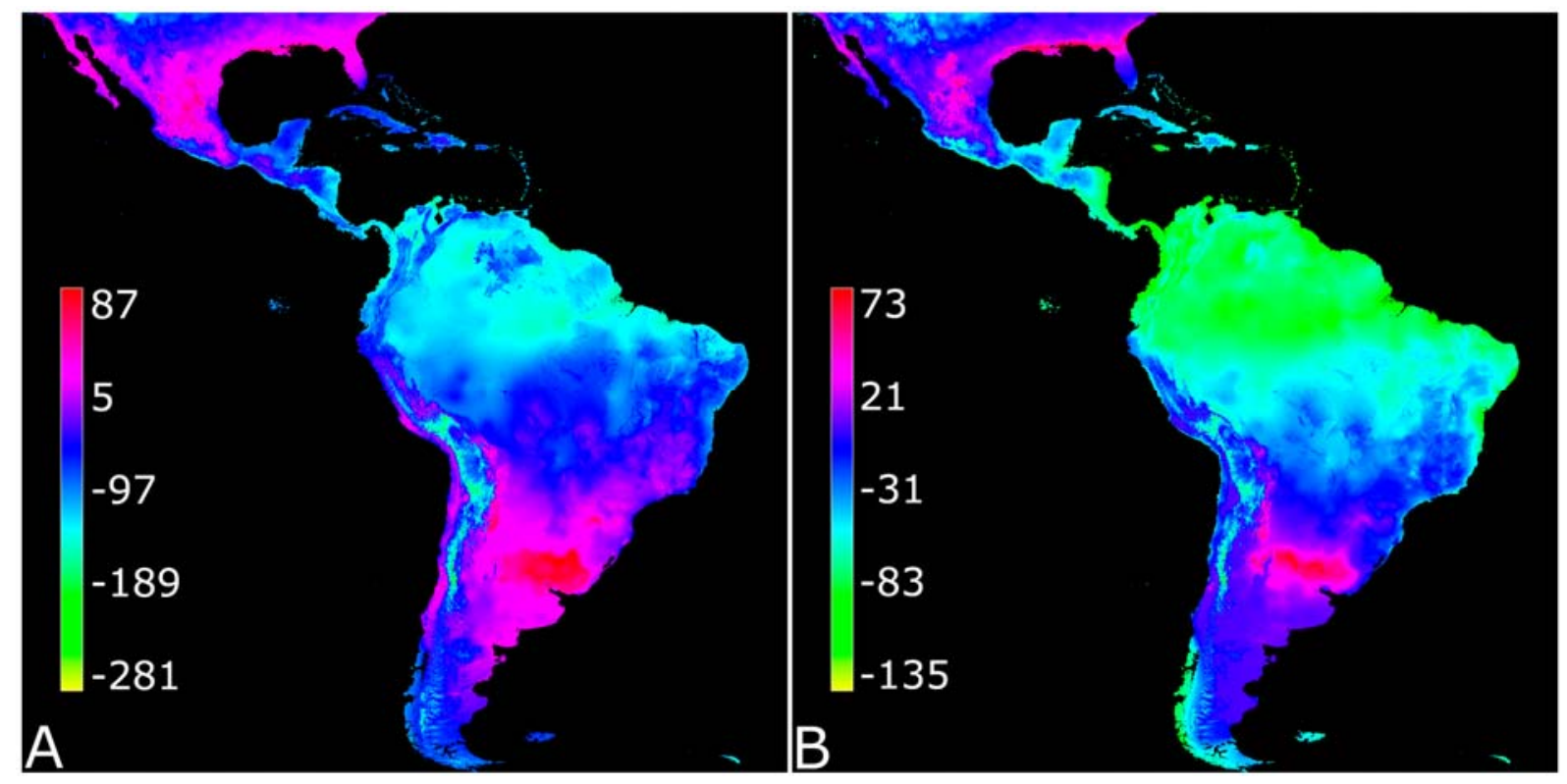

Results: According to both MESS analyses, the North-Eastern region of Argentina and Florida display climatic characteristics, in terms of coldness, similar to those of A) the urban areas and populated places in Israel and B) the entire geographic region of Israel. To a lower extent, other regions of Mexico and South USA also display locally similar cold temperatures according to the MESS analyses. Yet, no W. auropunctata occurrences are known in these regions. 
Appendix S3: Details on the amplification and sequencing protocols of the mitochondrial DNA of cytochrome oxydase (COI) sequences.

LCO and HCO universal primers (Folmer et al. 1994) were used for 97 individual DNA to PCR amplify a 710 bp fragment. However, we did not obtain any PCR product with this set of primer for 39 individuals from several localities (i.e. French Guiana, Guiana, Peru, Brazil, Panama, Surinam, Ecuador, Paraguay, Dominican Republic, Costa Rica and Coco Island). For these individuals, we combined the LCO primer with a new designed internal Reverse primer called newCOI-R (TGY-TGG-TAT-AAA-ATA-GGG-TCT-C) to amplify a 700 pb DNA fragment. For both sets of primers we used the same PCR mixtures as in Foucaud et al. (2007). Thermal cycling conditions were as follows: denaturation at $95^{\circ} \mathrm{C}$ for $3 \mathrm{~min}$, then 37 cycles of denaturation at $94^{\circ} \mathrm{C}$ for $1 \mathrm{~min}$, annealing at $55^{\circ} \mathrm{C}\left(48^{\circ} \mathrm{C}\right.$ for $\mathrm{LCO} /$ newCOI-R primer set) for $1 \mathrm{~min}$, and extension at $74^{\circ} \mathrm{C}$ for $1 \mathrm{~min}$, followed by a final extension at $74{ }^{\circ} \mathrm{C}$ for 10 min. PCR products were purified and sequenced on an ABI 3730 DNA sequencer (Applied Biosystems). Individual electropherograms were checked for eventual errors using Seqscape software (Applied Biosystems). 
Appendix S4: Results of Comparison of non-linear mixed model (nlme) according to a reparameterised Gompertz relationship versus linear model, to fit worker recovery following cold stress over the period of observation for each biogeographic origin, using the AIC criteria.

\begin{tabular}{|c|c|c|c|c|c|}
\hline \multirow{3}{*}{$\begin{array}{l}\text { Biogeographic origin } \\
\text { Mediterranean introduced } \\
\text { zone (i.e. Israel). }\end{array}$} & Model & AIC & logLik & L.Ratio & p-value \\
\hline & Gompertz & -898.1417 & 460.0709 & \multirow{2}{*}{620.6755} & \multirow{2}{*}{$<0.0001$} \\
\hline & Linear & -285.4663 & 149.7331 & & \\
\hline \multirow{2}{*}{ Tropical introduced zone } & Gompertz & -307.5932 & 164.7966 & \multirow{2}{*}{26.31007} & \multirow{2}{*}{$<0.0001$} \\
\hline & Linear & -289.2832 & 151.6416 & & \\
\hline \multirow{2}{*}{$\begin{array}{l}\text { Tropical native area in human- } \\
\text { modified habitat }\end{array}$} & Gompertz & -474.5748 & 248.2874 & \multirow{2}{*}{89.09958} & \multirow{2}{*}{$<0.0001$} \\
\hline & Linear & -393.4752 & 203.7376 & & \\
\hline \multirow{2}{*}{$\begin{array}{l}\text { Tropical native area in natural } \\
\text { habitat }\end{array}$} & Gompertz & -650.6933 & 336.3467 & \multirow{2}{*}{26.16102} & \multirow{2}{*}{$<0.0001$} \\
\hline & Linear & -632.5323 & 323.2661 & & \\
\hline \multirow{2}{*}{$\begin{array}{l}\text { Subtropical native marginal } \\
\text { zone (i.e. Argentina) }\end{array}$} & Gompertz & -291.48925 & 156.74463 & \multirow{2}{*}{309.572} & \multirow{2}{*}{$<0.0001$} \\
\hline & Linear & 10.08273 & 1.95863 & & \\
\hline \multirow{2}{*}{$\begin{array}{l}\text { Subtropical introduced zone } \\
\text { (i.e. Florida) }\end{array}$} & Gompertz & -168.7679 & 95.38395 & \multirow{2}{*}{80.4592} & \multirow{2}{*}{$<0.0001$} \\
\hline & Linear & -96.3087 & 55.154 & & \\
\hline
\end{tabular}

Results: In agreement with our comparison of model, the non-linear mixed model (nlme) according to a reparameterised Gompertz relationship always fits better the worker recovery following cold stress over the period of observation for each biogeographic origin compared to a linear model. 
Appendix S5: Details and results of statistical analyses based on general linear mixed models using both the proportion of surviving workers and time to reach half the maximal proportion of recovered workers after cold stress as response variables.

\section{Analytical methods:}

We assessed the effect of the biogeographic origin of each population on the maximal proportion of surviving workers observed throughout the experiment and the time to reach half the maximal proportion of surviving workers. The maximal proportion of surviving workers in populations was determined regardless of the time at which this maximum was reached. The biogeographic origin of each population was included as a categorical fixed factor (six levels: native area in natural habitats, native area in human-modified habitats, area of introduction in tropical zone, Florida in subtropical zone, Argentina in subtropical zone and area of introduction in the Mediterranean zone), whereas run number and population locality (nested in the "biogeographic origin” factor) were considered as random factors. For the maximal proportion of surviving workers, we used a general linear mixed model to consider binomial error terms and Laplace approximation to estimate parameters. The significance of the fixed factor was assessed in a likelihood ratio test. We used generalized linear mixed models (using GLMER in R) to assess the effect of the origin of each population on the time to reach half the maximal proportion of surviving workers. Gaussian error terms were considered and we used restricted maximum likelihood approximation (REML) to estimate parameters. The significance of the fixed factor was assessed in a likelihood ratio test. We then compared the time taken to reach half the maximal proportion of surviving workers for each origin of populations in Student's $t$ tests. 


\section{$\underline{\text { Results }}$}

\section{Maximal proportion of surviving workers after cold shock}

The table below indicates the mean proportions of surviving workers from populations of different biogeographic origins after cold shock at $2^{\circ} \mathrm{C}$ for 16 hours and the results of the general linear mixed model for populations from the introduced area in the Mediterranean region (Israel) as the baseline level.

$\underline{\text { Biogeographic origin }}$

Introduced area in the Mediterranean zone Native area, in natural habitats

Native area, in human-modified habitats Introduced area in the tropical zone Florida in subtropical zone Argentina in subtropical zone
Std. Mean Estimate Error Z Value P-Value

$\begin{array}{lllll}0.98 & -0.01799 & 0.10226 & -0.176 & 0.86034 \\ 0.33 & -1.13936 & 0.18707 & -6.091 & 1.13 \times 10^{-9} \\ 0.57 & -0.56064 & 0.16441 & -3.41 & 6.50 \times 10^{-4} \\ 0.56 & -0.57968 & 0.18799 & -3.084 & 2.05 \times 10^{-3} \\ 0.96 & -0.02297 & 0.20388 & -0.113 & 0.91 \\ 0.88 & -0.11157 & 0.23117 & -0.483 & 0.63\end{array}$

\section{Time to reach half the maximal proportion of surviving workers after cold stress}

Our comparison of models revealed that the biogeographic origin of populations had a significant effect on worker survival $\left(\mathrm{p}\right.$-value $\left.=5.15 \times 10^{-4}\right)$. Time to reach half the maximal proportion of surviving workers was significantly shorter for Israeli populations (mean = 42.60) than for tropical introduced populations (mean $=111.73$, $\mathrm{p}$-value $=1.57 \times 10^{-6}$ ) or populations originating from the native area, whatever the type of habitat (human-modified habitat: mean $=86.87$, -value $=1.82 \times 10^{-4}$ or natural habitat: mean $=117.5$, -value $=$ $\left.3.80 \times 10^{-5}\right)$. Workers from populations established in Florida (mean $=81.0$, $\mathrm{p}$-value $=7.54 \times 10^{-}$ ${ }^{5}$ ) recovered also slower than workers from Israeli populations. It seems that workers from Argentina recovered faster $($ mean $=14.49)$ than all populations tested in this study. However, 
this result must be interpreted carefully as these Argentinean populations were tested independently at the SABCL laboratory (Buenos Aires, Argentina) and this measure (i.e. time to reach half the maximal proportion of surviving workers after cold stress) is sensible to how workers were considered by observers as recovered. 
Appendix F1: Map of sites sampled for the phylogeographic analyses. Black dots correspond to sampled populations for which both mtDNA and microsatellites were analysed. Black crosses correspond to population samples used for mtDNA analyses only. Sites are named as follow: country of origin, reproductive system characterising the sampled population (S: Sexual, C: Clonal and unknown otherwise), site number. For instance: F. Guiana S1 is the site 1 of French Guiana in which the sampled population was known to be sexual.

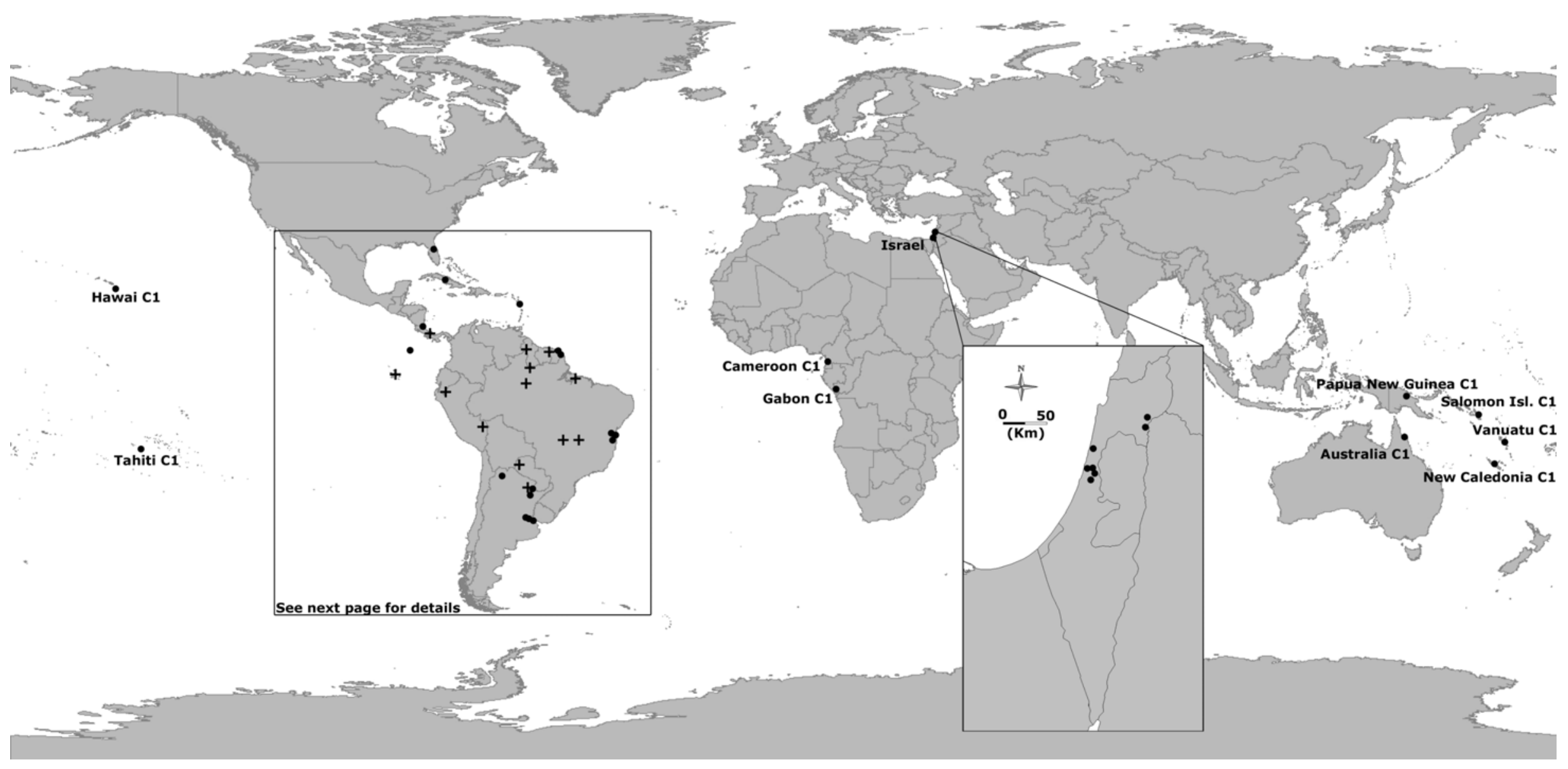




\section{Appendix F1 continued:}

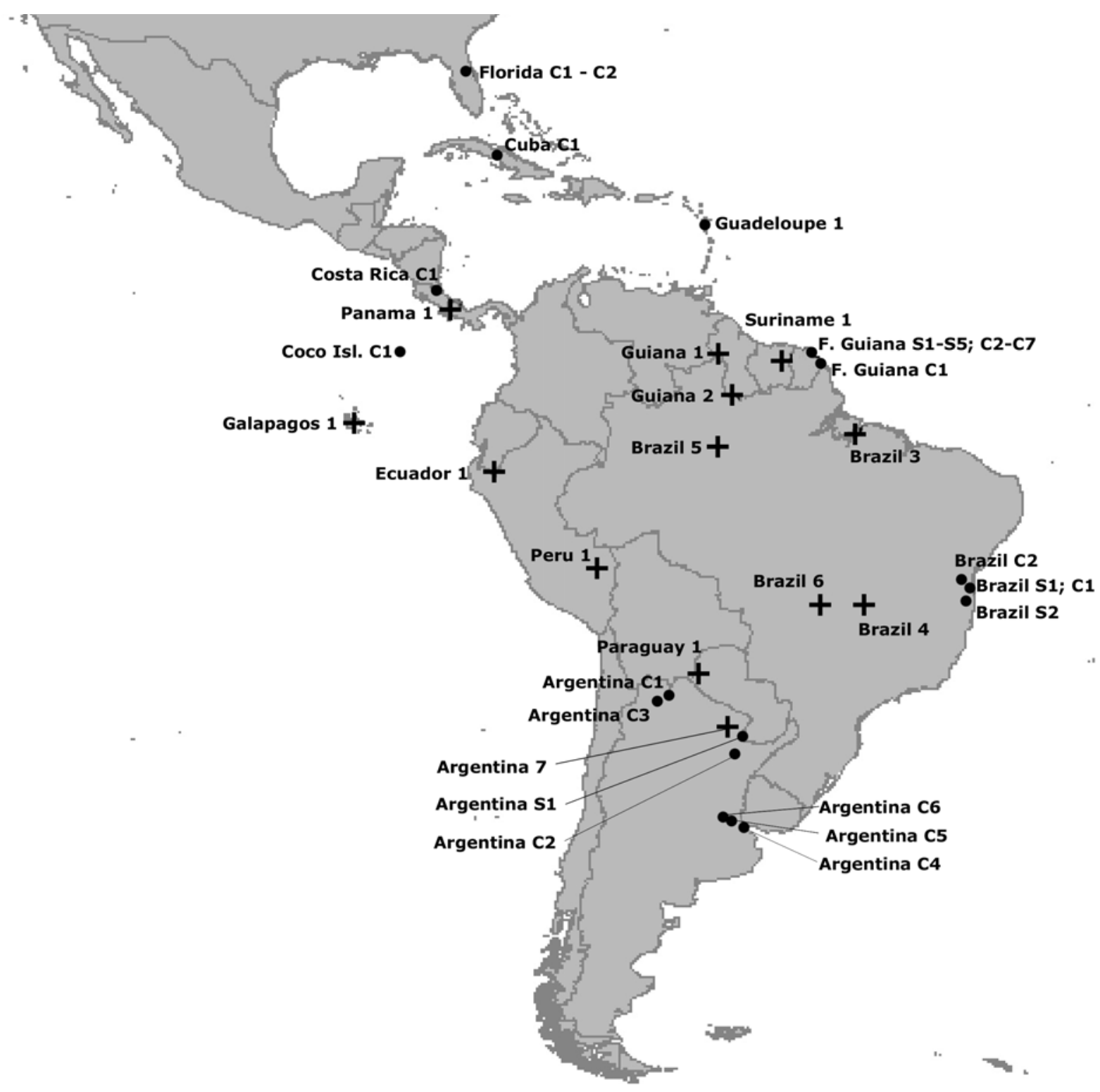

